\title{
Bumble bee species distributions and habitat associations in the Midwestern USA, a region of declining diversity
}

\author{
Jessie Lanterman Novotny ${ }^{1,3}$ (D) . Paige Reeher ${ }^{2,4}$ (D) Megan Varvaro ${ }^{1}$ (D) \\ Andrew Lybbert ${ }^{1,5}$ (D) Jesse Smith ${ }^{2,6} \mathbb{D} \cdot$ Randall J. Mitchell $^{2} \mathbb{D} \cdot$ Karen Goodell $^{1} \mathbb{D}$
}

Received: 8 July 2020 / Revised: 30 December 2020 / Accepted: 10 January 2021 /

Published online: 7 February 2021

(c) The Author(s) 2021

\begin{abstract}
Bumble bees (Bombus spp.) are important pollinators, yet rapidly declining globally. In North America some species are thriving while others are nearing extinction. Recognizing subtle differences in species' biology and responses to environmental factors is required to illuminate key threats and to understand their different population trajectories. We intensively surveyed bumble bees in Ohio, USA, along the receding southern boundary of many species' ranges, to evaluate current conservation status of the state's species. In 318 90-min field surveys across two consecutive years we observed 23,324 bumble bees of 10 species visiting 170 plant species. Habitat, landscape, latitude, and their interactions significantly influenced bumble bee abundance, species richness, and community composition during peak season. Sites planted with flowers yielded more bumble bee individuals and species than did sites not planted with bee food plants. Bombus impatiens, B. griseocollis, and $B$. bimaculatus comprised $93 \%$ of all observations. Their abundances all peaked in habitats planted with wildflowers, but there were species-specific responses to local and landscape factors. Three less common species (B. fervidus, B. vagans, and B. perplexus) were more likely to be found in forested landscapes, particularly in the northeastern portion of the state. Bombus perplexus was also affiliated with planted urban wildflower patches. These results provide a strong starting point for future monitoring and conservation intervention that targets less common species. A quantitative synthesis of detailed state-level and regional datasets would allow additional insight into broad scale patterns of diversity in bumble bee communities and species conservation trajectories.
\end{abstract}

Keywords Bombus $\cdot$ Community ecology $\cdot$ Conservation $\cdot$ Landscape ecology $\cdot$ Planted pollinator habitat $\cdot$ Statewide survey

Communicated by Nigel E. Stork.

Jessie Lanterman Novotny

JessieLantermanNovotny@gmail.com

Extended author information available on the last page of the article 


\section{Introduction}

Bumble bees (Bombus) are conspicuous eusocial insects that are critically important pollinators in both natural and agricultural habitats (Losey and Vaughan 2006; Kremen et al. 2007; Goulson 2010). Though most species are highly generalized foragers, bumble bees can play unique roles in plant-pollinator interaction networks by using their long tongues to access flowers with deep corolla tubes, by buzz pollinating flowers, and by prying open large closed flowers (Macior 1969; Heinrich 1976; Russell et al. 2017). Evidence indicates that bumble bees are declining over broad areas of the globe (Goulson et al. 2008; Cameron and Sadd 2020), including in North America (Grixti et al. 2009; Cameron et al. 2011; Colla et al. 2012). The erosion of bee diversity, in general, is associated with increased food stress from reduced floral diversity, continuing habitat loss, increased pesticide use, and disease (Cameron et al. 2011, 2016; Goulson et al. 2015). However, some species of bumble bees have suffered greater losses than others (Cameron and Sadd 2020). Among North American species there are many questions, but few answers, as to why some species appear to be thriving and others nearing extinction. Subtle differences in phenology, habitat use, diet breadth, nesting behavior, and responses to environmental stressors of North American bumble bee species may contribute to their current status and differing population trajectories (Williams et al. 2009; Williams and Osborne 2009; Wood et al. 2019; Liczner and Colla 2020). Baseline information on current abundances and distributions are uneven and incomplete, especially for North American species (Colla and Packer 2008; Richardson et al. 2019; Wood et al. 2019). In this study we focus on Midwestern USA bumble bee fauna habitat affiliation and environmental drivers of community structure.

Conservation of bumble bees depends on a strong understanding of both the natural and anthropogenic factors that determine the availability of key resources (Roulston and Goodell 2011; Cariveau and Winfree 2015), and these factors are likely to act on a range of spatial scales. At the local level bees can respond directly to the availability of suitable foraging, nesting, and overwintering sites in different habitats (Carvell et al. 2011; Lanterman et al. 2019). At the landscape level they respond to the mosaic of suitable habitats in the surrounding area (at a scale of several kilometers) and the quality of the intervening matrix that determines their connectivity (Hines and Hendrix 2005; McFrederick and LeBuhn 2006; Heard et al. 2007; Ahrné et al. 2009; Ropars et al. 2020). At the regional level, presence of bumble bee species may vary with latitude, altitude, and other large-scale features that determine whether a location lies within the physiological tolerance of each species (Hines 2008; Dohzono and Suzuki 2010; Williams et al. 2014). Bumble bee communities can be shaped further by competition, predation, pathogens, floral hosts, and restoration and management activities (Goulson 2010). Biological differences among species interact with these environmental factors to influence their distribution, abundance, and susceptibility to population declines (Schochet et al. 2016).

The state of Ohio is situated at the convergence of the Midwestern and the Northeastern regions of the United States. A total of 54\% of Ohio's land is farmed (USDA 2019), including crops that benefit from bumble bee pollination services (Park et al. 2016; McGrady et al. 2020). Of the twenty species of bumble bee historically documented in Ohio, only half of them have been seen regularly in the last century (Lanterman et al. 2019). Bombus affinis, listed as endangered on the IUCN Red List in 2015 (Hatfield et al. 2015) and federally endangered in 2017 (Christopher 2016), was last seen in Ohio in 2013 (specimen vouchered at the Toledo Zoo); B. terricola, federally identified as a species of concern in 2016, has not been recorded in the state since 1981 (specimen vouchered at the Ohio 
State University C.A. Triplehorn Collection). However, both can still be found in nearby states. Furthermore, many North American Bombus have a southern range margin in or near Ohio (Colla et al. 2011). Lower latitude boundaries appear to be shifting northward, and ranges are contracting for many northern hemisphere Bombus species in response to a changing climate (Kerr et al. 2015). Therefore, Ohio is well positioned to study changes in bumble bee species distributions and community composition along the southern boundary in the northcentral and eastern USA. Deeper knowledge of species distributions and habitat associations in Ohio may illuminate key threats, help identify strategies to slow losses of declining species, and predict future vulnerability of currently stable species (Williams et al. 2009; Kerr et al. 2015).

The burgeoning initiatives to conserve, improve, and construct pollinator habitat will benefit from solid bumble bee distribution data on multiple spatial scales. Rigorous datasets on bumble bee species' habitat affinities will allow local habitat managers to target at-risk species and evaluate which interventions most effectively promote those species (Liczner and Colla 2020). To date, however, no studies have thoroughly documented the distribution and abundance of Bombus across the state of Ohio, nor have any studies investigated species-specific habitat and landscape associations that might explain variation in their distribution. Because the majority of species found in midwestern North America have low relative abundances (Preston 1948), intensive sampling is required to generate data sets large enough to evaluate patterns of the distribution and abundance of less common species (Cameron et al. 2011).

We conducted a comprehensive two-year survey of bumble bees in Ohio to document their current abundance, distribution, habitat use, and response to various environmental factors. We aimed to sample intensively enough to not only document general drivers of bumble bee abundance and diversity, but to discern species-specific patterns of habitat use. We addressed the following questions: How are bumble bee diversity, abundance, and community composition affected by local flower availability and landscape context? How do species differ in their habitat associations? Are there geographical or latitudinal patterns in species occurrence or relative abundance across the state of Ohio?

\section{Methods}

\section{Study sites}

We conducted 318 90-min surveys of bumble bees (Bombus spp.) and wildflowers at 228 locations in Ohio, U.S.A, between June and August 2017 and 2018. Study sites consisted of flower-rich patches of foraging habitat greater than 0.4 ha (mean $9.0 \pm 15.2$, $\max 134.4 \mathrm{ha})$ that were at least $2 \mathrm{~km}$ apart, and included public lands $(\mathrm{n}=198)$, roadside patches of wildflowers $(n=41)$, private nature preserves $(n=49)$, and private residential properties $(n=30)$. Sites were classified into the following habitat categories based on their dominant vegetation and management history: natural field, shrubby successional old field, planted hayfield, planted restored meadow, planted urban patch, planted restored roadside, or roadside (Electronic Supplementary Material, Table S1). Planted sites included pollinator-friendly and native prairie wildflower species. The extent of suitable foraging habitat at each site was first ground truthed during field surveys and later digitized using Google Earth software. 


\section{Bee field surveys}

We based our sampling design on Ward et al. (2014) and the US Fish and Wildlife $B$. affinis survey protocol (2017). Bee surveys were performed between the hours of 0900 and 1800 on days without precipitation, with little or no wind, and with air temperature above $21{ }^{\circ} \mathrm{C}$. Upon each site visit, a team of one to four trained observers recorded bee visits to flowers for a total of 90 person minutes, not including netting and handling time. If there was one observer, that person netted for the full $90 \mathrm{~min}$. If two observers were present, each netted independently for $45 \mathrm{~min}$. For three or four observers, the time per person was reduced accordingly. The observers spread out and walked slowly through the best available foraging habitat, recording all bee visits to flowers and the flower species on which they were observed. We recorded species identity and social caste of each bumble bee. Bumble bees were either identified to species on the wing, or were netted, identified using a field guide (Colla et al. 2011), photographed if needed for identification confirmation, and re-released on site. To minimize our impact and because of the large number of bumble bees observed at some sites (as many as 452 in a single 90-min survey), the majority of bees were not collected. We searched systematically, moving between flower patches often, to minimize double-counting of individual bees.

\section{Plant field surveys}

We estimated the available flower resources for bees at each site on every visit by surveying flowers along four $25 \mathrm{~m}$ by $1 \mathrm{~m}$ transects $\left(100 \mathrm{~m}^{2}\right.$ total area). The four transects were placed within the site in a way that represented the flower community in the area where bees were surveyed. For instance, if we had surveyed flowers along the forest edge, within mowed paths, and in open field, we would haphazardly place transects within each of these areas to capture the primary floral resources used by bumble bees, choosing areas roughly based on the amount of time we spent surveying each. In each transect, we recorded the number of flower units of each species in bloom. Species that exceeded 1000 flower units per $25 \mathrm{~m}$ transect were recorded as "1000." Flower units were defined in "bee walkable clusters," with one unit as the number of flowers a bee could visit by walking before it would have to fly to the next cluster (Saville 1993). What constituted a flower unit was defined separately for each plant species (but consistently across all observers), based on floral morphology and on observations of bee foraging behavior. Plant species were identified using a field guide (Newcomb 1989) or were photographed for later identification.

\section{Landscape assessment}

To evaluate the landscape around each site, we used remotely-sensed data to calculate the proportion of forest (deciduous and conifer), shrub, fields (alfalfa, clover, other hay, idle cropland, grassland, pasture, and developed open space), developed areas (low, medium, and high intensity), wetlands (woody and emergent herbaceous), pollinatorsupporting crops (fruits and vegetables that flower before harvest), and non-pollinatorsupporting crops (grains, tree crops, sod-grass, and other crops that are harvested before flowering) using ArcGIS software (ESRI 2016). This simplified land cover classification scheme was modified from the USDA Cropland Data Layer (CDL 2018 version; USDA 
2019). We considered landscape composition at three spatial scales-a 1.0-km, 1.5-km, and $2.0-\mathrm{km}$ buffer radius areas from the geographic site centroid-based on bumble bee foraging distances reported in the literature (Dramstad 1996; Osborne et al. 1999; Walther-Hellwig and Frankl 2000a, b; Wood et al. 2015). We used generalized linear models and AICc values to determine that the $2.0-\mathrm{km}$ landscape scale better reflected variation in Bombus abundance and richness.

\section{Data analysis}

We restricted our flower richness and abundance measures to only include flower species that were visited by at least one bee during our surveys. For most analyses, we grouped two morphologically similar bumble bee species-B. auricomus and B. pensylvanicusbecause not all were distinguished in the field, and they accounted for a low proportion of observations in any given survey. Two rare species in our dataset-B. citrinus (3 individuals observed) and $B$. borealis (a single individual) - were retained for abundance and richness analyses but omitted from community ordination to avoid their disproportionate influence on pairwise distances among sites and ordination configuration (McCune et al. 2002). Abundance data were natural log transformed as needed to improve their fit to a Gaussian distribution. To assess differences in bee diversity between sites, independently of abundance, data were rarefied down to 19 bumble bees per survey and the average species richness of 1000 random bootstrap replicates was calculated (rrarefy function, 'vegan' package). Fifty surveys in which fewer than 20 bumble bees were found were excluded from rarefaction analysis. We were able to visit a minority of sites twice, but they were visited in different years and different times, so due to high background variation in bee survey yield they were treated as independent observations. Most analyses were conducted using R, version 3.5.3 (R Development Core team 2019). JMP software version 14 (2018) was used to construct generalized linear models with logit link functions on presence/absence data for rarer species.

We used multiple regression models to evaluate how habitat, flower resources, landscape, and time of season affected overall bumble bee abundance and diversity in our surveys. To investigate whether common species responded differently to environmental features, models were also constructed separately for each of the three most abundant species. Models of bumble bee abundance and raw and rarefied species richness were fitted with the following potential main effects: growing degree day (GDD; determined using the online calculator at https://www.oardc.ohio-state.edu/gdd/default.asp), latitude, flower abundance, flowering species richness, habitat type, and the proportion of forest (hereafter "forest") and urban developed area (hereafter "developed") in the landscape. We also included the two-way interaction terms between habitat and all local and landscape level variables that have been shown to modify the quality of a specific habitat for bumble bees (e.g., Ahrné et al. 2009, Cariveau and Winfree 2015; Carvell et al. 2011; Heard et al. 2007; Hines 2005; Lanterman et al 2019; Reeher et al. 2020; Schochet et al. 2016), as well as GDD, which helps account for phenological effects on bumble abundance and richness (Lanterman et al 2019). Finally, we included a flower abundance $\mathrm{x}$ flower richness interaction to help account for the overall availability of flower resources. A gaussian distribution was selected for each response variable based on the model adjusted $\mathrm{R}^{2}$ values under different distributions and Shapiro tests for normality of model residuals. Prior to model construction, we checked for collinearity of continuous predictor variables by calculating a Pearson correlation matrix. There was a moderate negative correlation between developed land and forest (Pearson $r=-0.53$ ); all others were less than 
0.5. Continuous predictor variables were standardized and centered by subtracting the mean from each observation then dividing by the standard deviation. For each model, we calculated Variance Inflation Factors (VIFs) for each independent variable and found no evidence of multicollinearity. To compare the amount of variance explained by each factor or interaction in our models, we calculated their partial eta-squared values (Richardson 2011). We used the Tukey procedure for pairwise contrasts of mean abundance and richness between all habitat types within the model framework (package 'lsmeans;' Lenth 2016). Complete model summaries are given in the Electronic Supplementary Material, Tables S2-S7.

We investigated the factors influencing the probability of occurrence of the less common species (B. fervidus, B. vagans, B. perplexus, B. auricomus, and B. pensylvanicus) using generalized linear models with a logit link function on presence versus absence data. We focused these analyses on broad-scale factors because we suspected that the presence/absence data would be less sensitive than abundance data to snapshot measures of local environmental quality, such as flower abundance and richness. Therefore, for each of these five species we analyzed its presence versus absence as a function of habitat type, landscape context, latitude, and their first-order interactions. We used the Firth adjusted maximum likelihood method to estimate parameter values. Non-significant terms were dropped from models sequentially, starting with the lowest likelihood ratio chi square value, and each reduced model was compared to the previous using AICc. For each species we retained the model that had the most independent variables and an AICc at least 2 lower than the next best fit model. There were not enough sightings of $B$. citrinus or $B$. borealis to analyze.

To visualize bumble bee community composition, we used non-metric multidimensional scaling (NMDS) ordination (metaMDS function, 'vegan' package; Oksanen et al. 2016). We tested for differences in community composition by habitat type and month using permutational analysis of variance adonis tests (adonis function, 500 permutations, 'vegan' package) based on Bray-Curtis dissimilarity between sites. To visualize the influence of landscape and other continuous variables on bee community composition, we fitted significant predictor vectors to the ordination plot using the envfit function in the 'vegan' package.

Indicator species analysis was used to determine if bumble bee species were associated with particular habitat types (indval function, 'labdsv' package, 500 iterations; Roberts 2016). An indicator value was calculated for each species - habitat combination as the product of the relative frequency and relative average abundance of a species at sites of a particular habitat type, taking into account the number of sites in that habitat group.

To visualize differences in habitat use by each bumble bee species, we standardized abundance values for the June-July samples by dividing the mean abundance per survey by the maximum value for that species across habitats. These values were plotted using radar charts. Bombus auricomus and pensylvanicus were plotted separately for this analysis using the subset of individuals from the $B$. auricomus/pensylvaniucs morphotype that we had identified to species with confidence.

\section{Results}

In 318 surveys ( $477 \mathrm{~h}$ ) we recorded 23,324 bumble bees representing 10 species (Table 1 ), visiting 170 flowering plant species. In an average 90-min field survey, we observed $73 \pm 65$ SD bumble bees (range $2-452$ ) of $3.9 \pm 1.2$ species (range $1-7$ ).

Three species accounted for $93 \%$ of all bumble bee sightings: Bombus impatiens (50\%), B. griseocollis (30\%), and B. bimaculatus (14\%). These three abundant species 


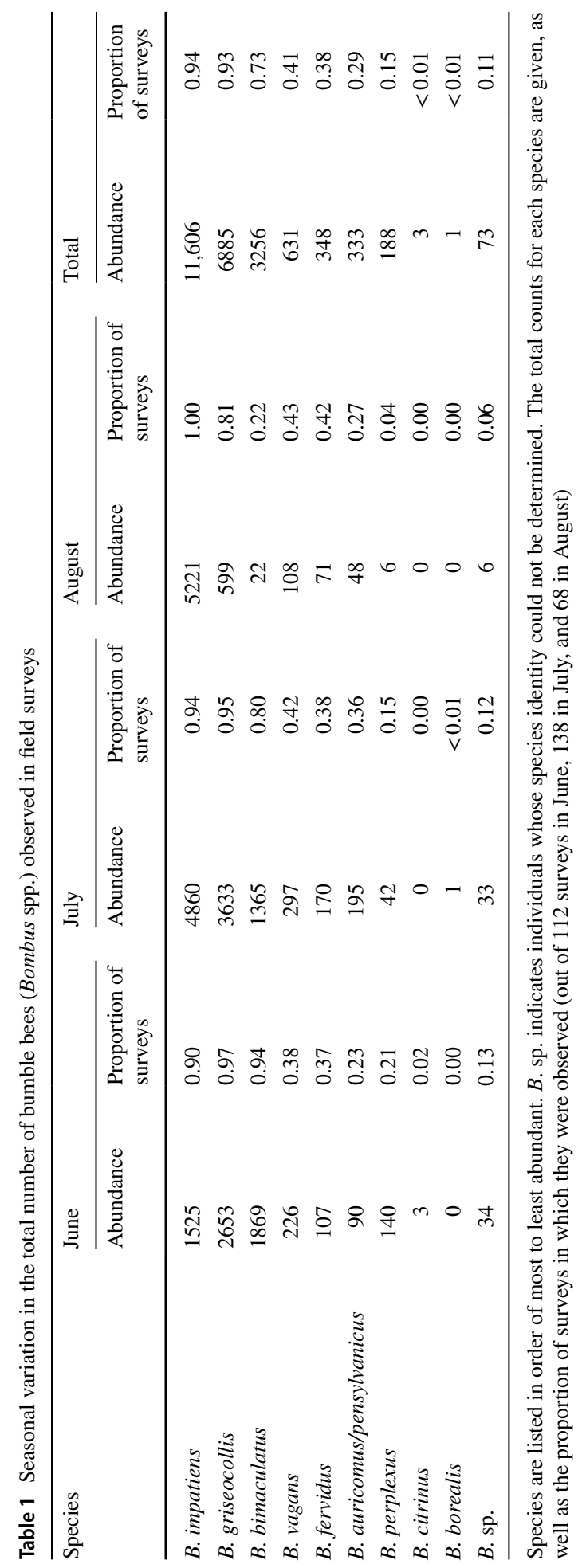


each occurred in over $90 \%$ of surveys (Table 1). Bombus vagans and B. fervidus were each found in approximately one-third of all surveys, and B. perplexus in $15 \%$ of surveys. The nest parasite Bombus citrinus was observed infrequently. A single worker of $B$. borealis was observed in July in the northeast of the state, apparently the first sighting in Ohio since the 1950s, according to records from the Cleveland Museum of Natural History Insect Collection and the C.A. Triplehorn Insect Collection at the Ohio State University (specimen verified and vouchered at the Cleveland Museum of Natural History). We did not observe two species of particular conservation concern that were historically found in Ohio (B. affinis and B. terricola), despite intensive survey effort and inclusion of suitable habitat in and near locations where they were most recently sighted.

Bombus impatiens was the most abundant bumble bee species in half of the surveys (152 out of 318). In a quarter of the surveys (88 out of 318), this species was more than twice as abundant as the next most numerous. Bombus impatiens increasingly dominated surveys as the season progressed (accounting for $22 \%$ of Bombus sightings in June, $45 \%$ in July, and $85 \%$ in August, Fig. 1, Table $1 ; F=14.37, d f=3,314, p<0.01$ ). During late summer surveys bumble bee abundance per survey increased ( $59 \pm 45$ bumble bees per survey in June, $77 \pm 70$ in July, $89 \pm 78$ in August) but diversity declined ( $4.1 \pm 1.2$ species in June; $4.0 \pm 1.2$ in July; $3.2 \pm 1.1$ in August). Therefore, August samples were excluded from further analyses, and only June and July surveys (peak season for all other bumble bee species) were used in the analyses below.

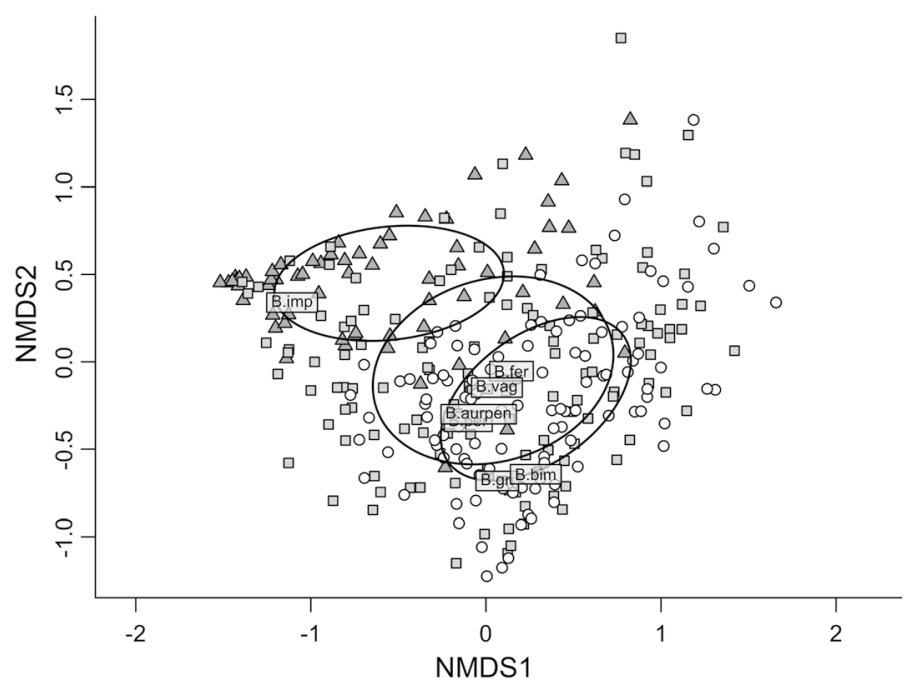

Fig. 1 NMDS ordination of seasonal variation in bumble bee species assemblage (based on Bray-Curtis distances, final stress with 3 axes $=0.11, n=318$ surveys). White circles represent June surveys, light gray squares July, and dark gray triangles August (adonis test by month $F=14.37, R^{2}=0.12, d f=3,314$, $p<0.01$ ). Black ellipses represent $1 \mathrm{SD}$ areas around group centroids. Black squares show the position of each bumble bee species. Bombus species are abbreviated as follows (top to bottom): B.imp (B. impatiens), B.fer (B. fervidus), B.vag (B. vagans), B.aur/pen (B. auricomus/pensylvanicus), B.per (B. perplexus), B.bim (B. bimaculatus), and B.gri (B. griseocollis) 


\section{Trends in overall bumble bee abundance, richness, and community composition}

Sites intentionally planted with flowers (seeded hayfields, restored meadows, restored roadsides, and planted urban patches) consistently yielded high numbers of bumble bees (planted $85 \pm 68, n=142$; unplanted $48 \pm 42, n=108$ ) and more than four species (planted $4.3 \pm 1.2$, unplanted 3.7 \pm 1.2 ). Bumble bee abundance per survey in June and July was highest in hayfields $(115 \pm 74, \mathrm{n}=7)$, and lowest in early successional natural fields $(40 \pm 31, n=52)$. Planted urban patches also attracted large numbers of bumble bees $(89 \pm 102, \mathrm{n}=13)$ and had relatively high species richness $(4.5 \pm 1.0)$.

Total bumble bee abundance varied widely (from 2 to 377 in June/July surveys) and responded strongly to habitat in multiple regression models. Landscape factors and habitat by latitude interactions explained small, but significant amounts of the variation in abundance (Table 2). Bumble bee abundance generally increased with the proportion of developed area and forest in the landscape (Electronic Supplementary Material Table S2), although species varied in their relationship with forest (see individual species analyses below). Habitat effects interacted with latitude such that bumble bee abundance increased with latitude in planted meadows, roadsides and urban patches (Table S2). Bumble bee abundance trended higher in sites with abundant flowers, but not significantly (Table 2). Note, there were no consistent differences between habitat types in flower abundance $(F=0.99, d f=6,246, p=0.43)$ or in flowering species richness $(F=0.78, d f=6,246, p=0.59)$.

We found between one and seven bumble bee species per survey (mean 4.0 \pm 1.2 ). Raw bumble bee species richness varied with habitat and the interaction between habitat and the amount of forest in the landscape (Table 2, Electronic Supplementary Material Table S3). In particular, Bombus species richness was greater in planted meadows than in early successional natural fields (according to Tukey's pairwise contrasts of abundance by habitat within the model framework, $t=3.20, d f=198, p=0.03$ ). Rarified bumble bee richness (standardized to 19 individuals per site) declined with flower richness but did not differ among habitat types (Table 2).

Bumble bee community composition varied with landscape setting (Fig. 2), and certain landscape factors emerged as important determinants of species' abundances (see individual species analyses below). In general, species assemblage was influenced by nearby forest (envfit vector correlation with NMDS axis 1 and 2 scores, $r^{2}=0.07$, $p<0.01)$, developed area $\left(r^{2}=0.03, p=0.04\right)$, and non-pollinator-supporting crops in the landscape $\left(r^{2}=0.03, p=0.02\right)$, in addition to GDD $\left(r^{2}=0.13, p<0.01\right)$. Although significant, the $r^{2}$ values indicating correlation between landscape components and bumble bee community composition were very low.

Community composition was also significantly, but weakly influenced by habitat type (adonis test $F=2.51, R^{2}=0.06, d f=6,246, p<0.01$; Fig. 2). We used radar plots to visualize more clearly the differences in habitat affiliations between species. Almost all species reached their maximum abundance in one of the planted habitats (Fig. 3), while only one reached maximum abundance in an unplanted habitat type (B. pensylvanicus on roadsides). Planted hayfields harbored the greatest abundances of three of the most common species, while several of the less common species were frequently encountered in planted roadsides (Fig. 3). However, those were some of the least abundant habitat types ( 7 planted hayfields and 11 planted roadsides sampled in June/July), so the results should be interpreted with caution. According to indicator species analysis, Bombus bimaculatus $(i v=0.61$, freq $=216, p<0.01)$ and B. griseocollis $(i v=0.65$, freq $=240$, 


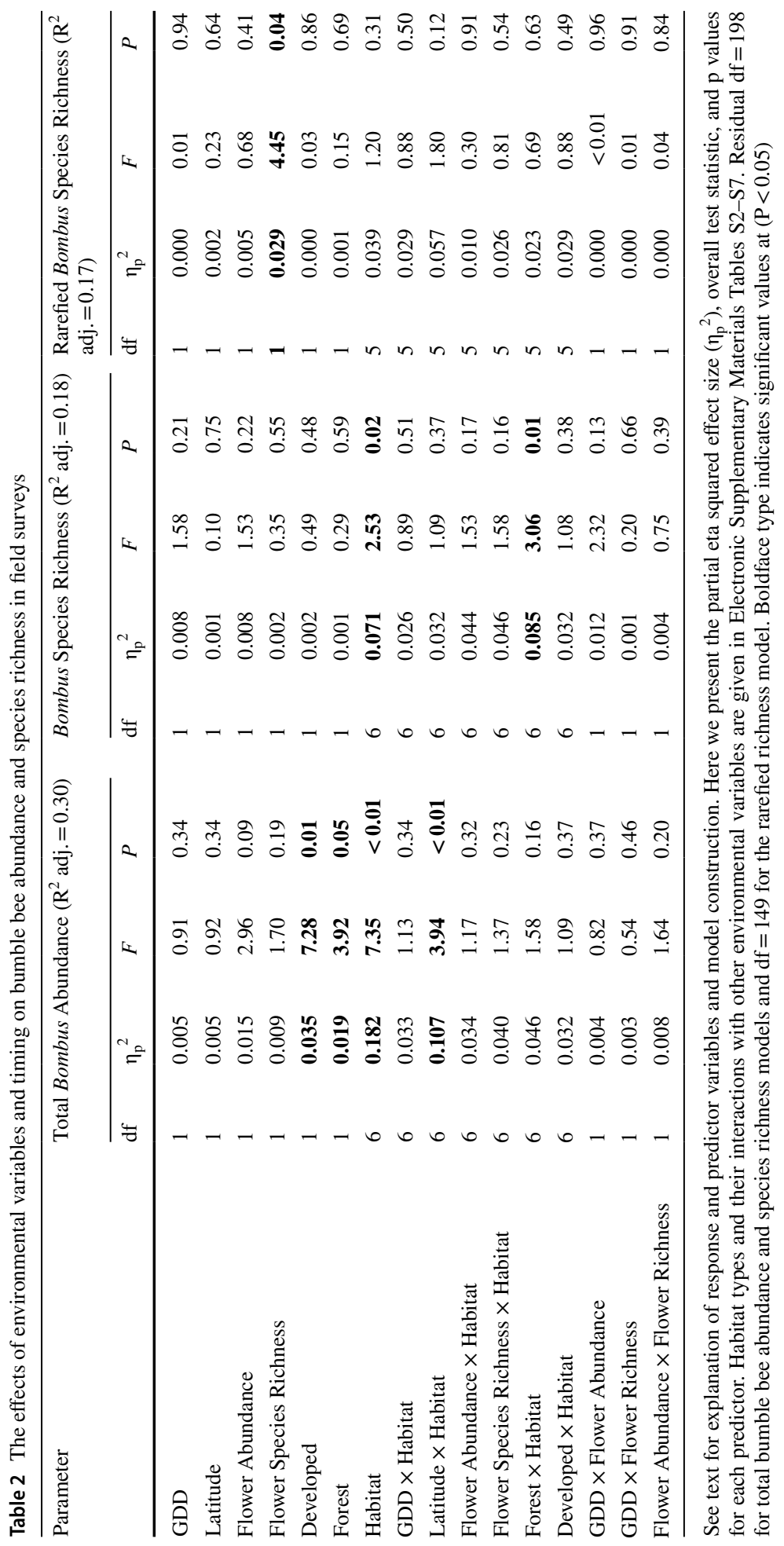




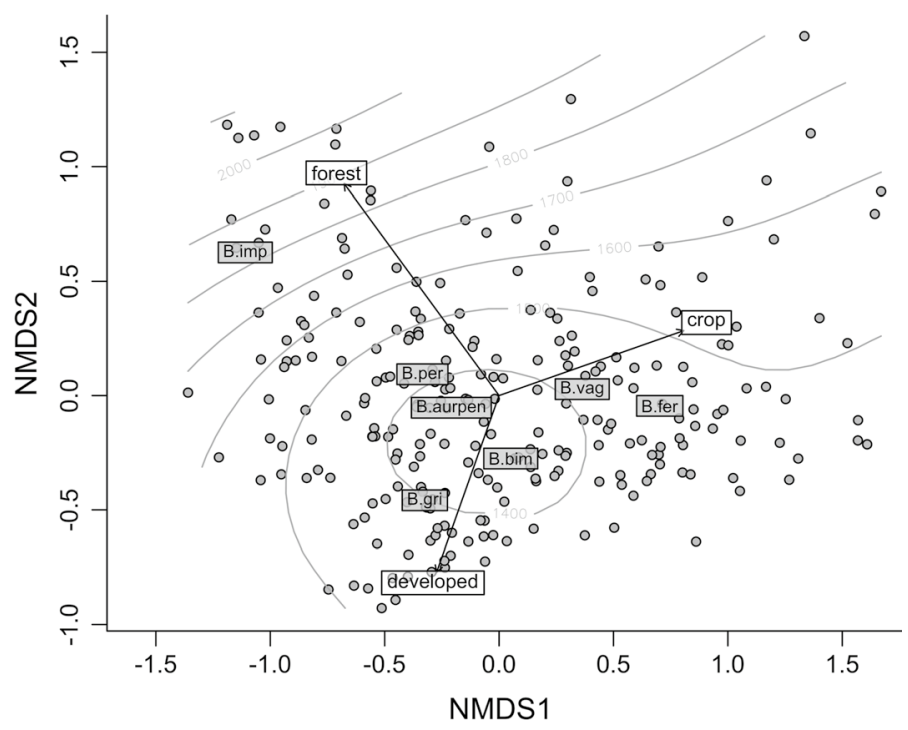

Fig. 2 NMDS ordination of bumble bee species assemblage in June and July field surveys (based on BrayCurtis distances, final stress with 3 axes $=0.11, n=250$ field surveys). Significant effects of $\%$ forest, $\%$ developed area, and \% non-pollinator-supporting crops in the landscape are shown as vectors. Growing degree day (GDD), which also significantly influenced bumble bee community composition, is shown as contour lines. The center of each species name text box indicates its position on the ordination. Species names are abbreviated as in Fig. 1

(a) More abundant species

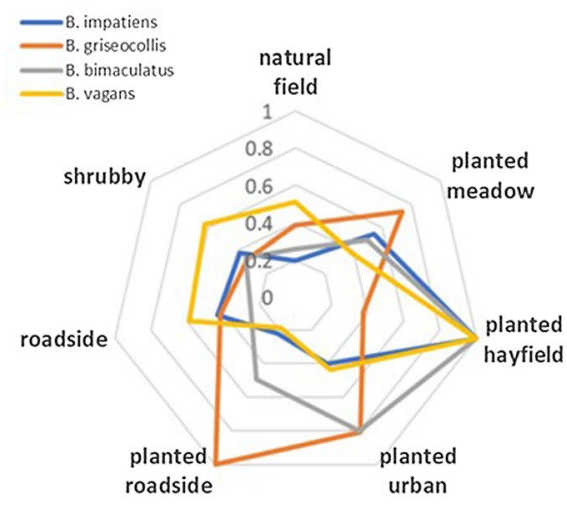

(b) Less abundant species

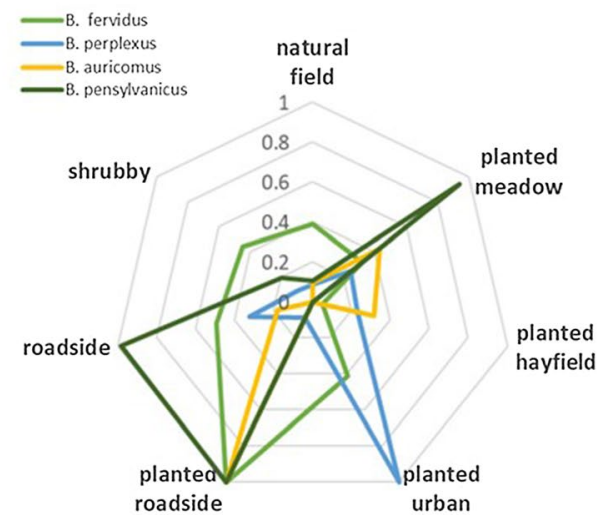

Fig. 3 Bumble bee abundance per survey for different habitat types. Values are habitat means for each species divided by the maximum value for any habitat for that species. The four most abundant species across all surveys are shown in panel $a$, and four less common species in panel $b$. The number of surveys in each habitat type was planted restored meadow (111), planted hayfield (7), planted urban patch (13), planted restored roadside (11), roadside (28), shrubby old field (28), and natural field / early successional field (52)

$p<0.01)$ were associated with habitats planted with wildflowers, rather than unplanted fields and roadsides (Fig. 3a). Bombus perplexus was associated with urban planted patches $(i v=0.22$, freq $=45, p=0.03$; Fig. 3b), and Bombus auricomus with planted 
roadsides $(i v=0.23$, freq $=34, p=0.02$; Fig. $3 b$ ). There were no significant habitat associations for $B$. pensylvanicus, likely due to low sample size $(n=28$ individuals identified with certainty). Shrubby and early successional natural field habitats were not favored by any bumble bee species.

\section{Trends in abundance of the three most common species}

Species-specific analyses of abundance of the three most common bumble bee species (B. impatiens, B. griseocollis, and B. bimaculatus) reveal similarities and differences in their responses to local, landscape, and geographic variables (Table 3). In multiple regression models there was a significant effect of habitat type on the abundances of all three species, primarily due to their high numbers in planted meadows and roadsides habitats (Table 3, Electronic Supplementary Materials Tables S5-S7). In models of Bombus impatiens abundance the effect of habitat interacted with latitude, increasing with latitude in planted meadows and urban patches. However, there were more urban patches available to sample in the northern part of the state than in the southern. Bombus griseocollis and $B$. bimaculatus were both significantly more abundant in planted meadows than in early successional unplanted fields (according to Tukey's pairwise contrasts of abundance by habitat within the model framework: B. griseocollis $t=-3.98, d f=198, p<0.01 ;$ B. bimaculatus $t=-5.02, d f=198, p<0.01)$. As for landscape scale and geographic factors, Bombus impatiens tended to increase with the proportion of developed land and forest in the landscape (Table 3, Electronic Supplementary Material, Table S5). Bombus griseocollis abundance also increased with percent developed land, but not with forest (Table 3, Table S6). Bombus bimaculatus abundance generally declined with GDD and latitude (Table 3, Table S7). However, this species did increase in abundance with latitude in certain managed habitats (significant latitude $\mathrm{x}$ habitat interaction for planted meadows, roadsides, and urban patches; Electronic Supplementary Materials, Table S7).

Bombus bimaculatus and B. griseocollis abundances were weakly positively correlated with one another on a site by site basis (June and July surveys only, Pearson correlation $r=0.12, t=1.90, d f=228, p=0.06)$. Bombus impatiens abundance was weakly positively correlated with that of $B$. griseocollis $(r=0.16, t=2.53, d f=239, p=0.01)$, but not with $B$. bimaculatus ( $r=0.06, t=0.88, d f=231, p=0.38$ ), likely because of the earlier and shorter period of activity of the latter species.

\section{Trends in presence/absence of the less common species}

The probability of site occupancy for the less common species (based on presence/absence data) showed that three species, B. fervidus, B. perplexus, and B. vagans, were more likely to be found at sites located in more forested landscapes (Table 4, Fig. 4) and at higher latitudes (Table 4, Fig. 5a-c). The positive effect of forest was especially strong for B. vagans (Fig. 4). The response to forest by B. fervidus varied with latitude; in northern latitudes the probability of occurrence increased strongly with forest, but in southern latitudes it declined slightly with the amount of forest in the landscape, despite similar ranges of percent forest across latitudes (Fig. 4 inset). In contrast, the predicted probability of B. pensylvanicus occurrence was negatively associated with latitude (Table 4, Fig. 5d) and forest (Table 4, Fig. 4), indicating that it was more common in open landscapes in the southern part of the state. The occurrence of B. auricomus, a species often reported to have a similar niche to the rarer B. pensylvanicus (Hobbs 1965; Liczner and Colla 2020), was 


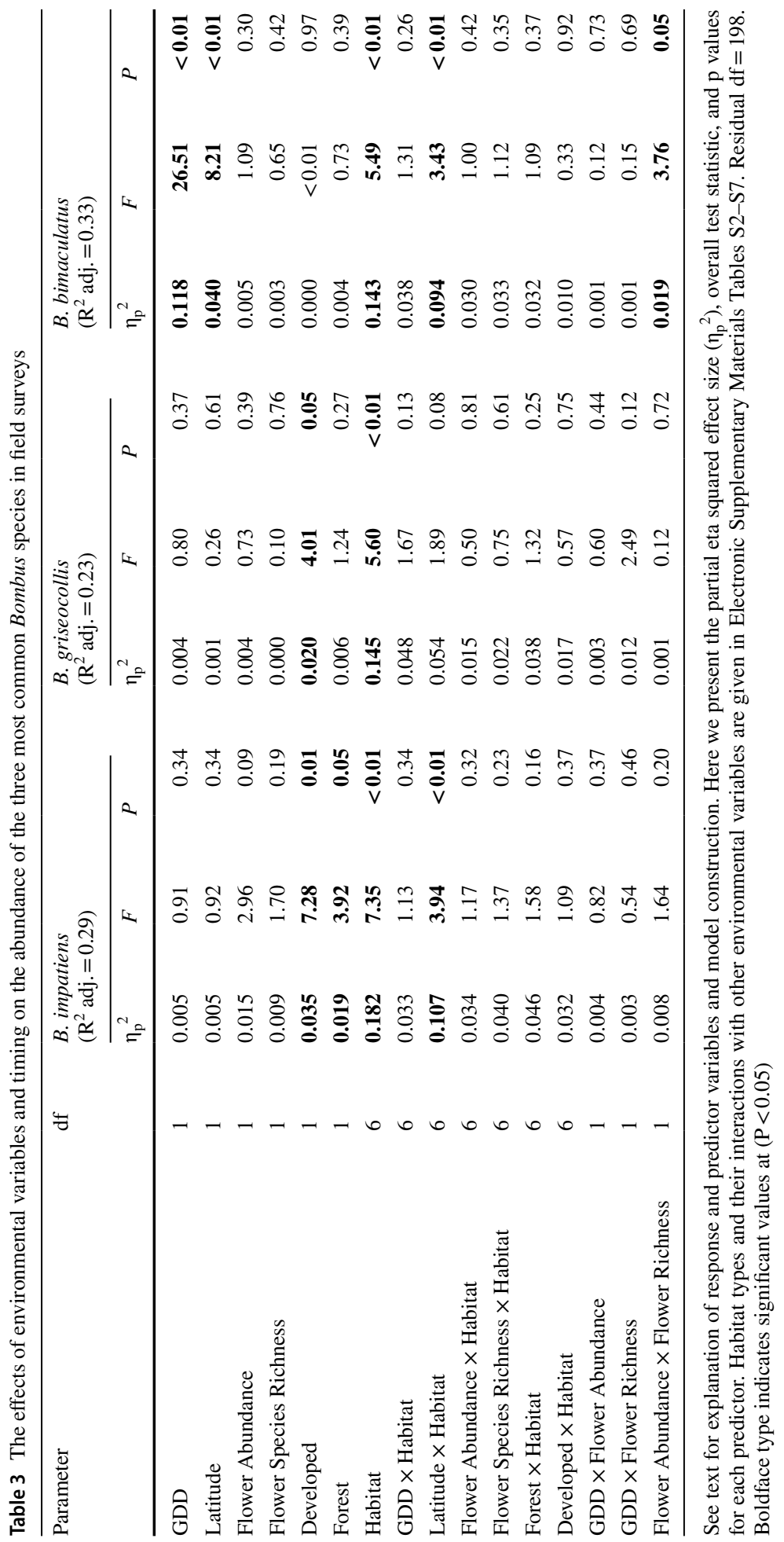


Table 4 Generalized linear models of the probability of occurrence of the rarer bumble bee species as a function of habitat, latitude, and landscape variables

\begin{tabular}{llrrrr}
\hline Species & Predictor (significant levels) & Estimate & SE & $\begin{array}{l}\text { Likelihood ratio } \\
\text { Chi-square }\end{array}$ & $p$ \\
\hline B. auricomus & Habitat & & & 21.260 & 0.002 \\
& (planted roadside) & 1.855 & 0.620 & 10.360 & 0.001 \\
B. fervidus & Forest & 0.316 & 0.128 & 6.339 & 0.028 \\
& Latitude & 0.325 & 0.150 & 4.840 & 0.012 \\
& Forest*Latitude & 0.357 & 0.132 & 8.570 & 0.003 \\
B. pensylvanicus & Forest & -0.643 & 0.308 & 6.020 & 0.014 \\
& Latitude & -2.080 & 0.625 & 21.100 & $<0.001$ \\
B. perplexus & Forest & 0.425 & 0.164 & 6.789 & 0.01 \\
& Latitude & 1.125 & 0.211 & 37.177 & $<0.001$ \\
B. vagans & Forest & 0.901 & 0.145 & 50.220 & $<0.001$ \\
& Latitude & 0.421 & 0.162 & 6.899 & 0.009 \\
& Forest*Latitude & 0.229 & 0.146 & 2.812 & 0.094 \\
\hline
\end{tabular}

Models shown are those with the best fit (lowest AIC value)

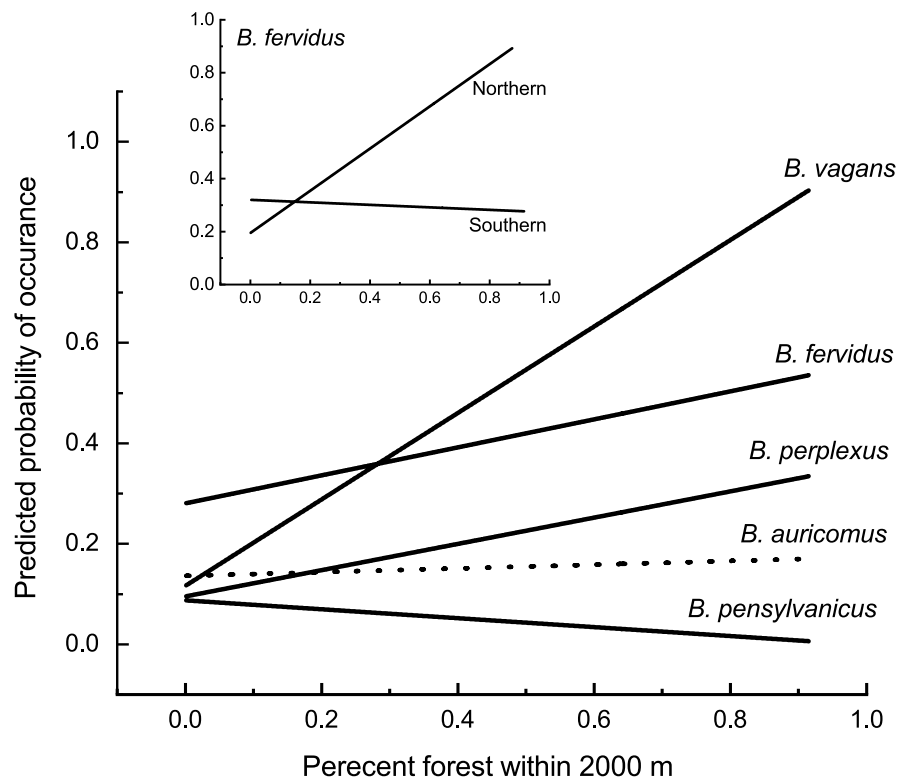

Fig. 4 Influence of forest cover on the likelihood of encountering the rarer species of bumble bee. The predicted probability of occurrence was generated using generalized linear models on presence/absence (logit transformed) at each sample site, analyzed separately by species (see Methods text). Shown are linear fits of the predicted probability of occurrence to percent forest in the landscape. Solid lines represent significant and dotted lines represent non-significant relationships. The inset represents the interaction between percent forest and latitude found for Bombus fervidus (Table 4) by showing the relationship for Northern and Southern occurrences of Bombus fervidus. Northern includes sites located at higher than mean latitude $($ mean $=40.51044)$. Southern includes sites located at lower than mean latitude 

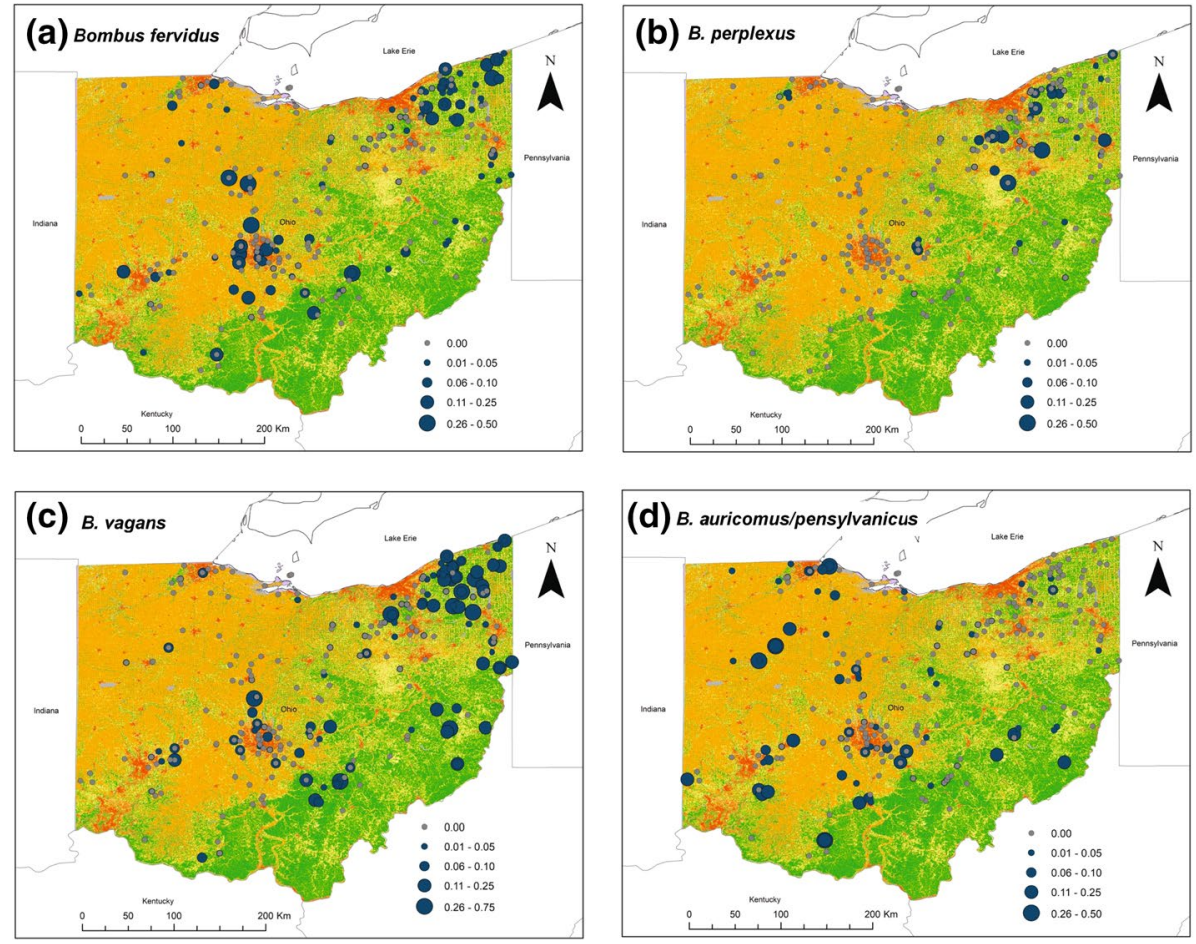

Fig. 5 Distribution and relative abundance of bumble bee species of conservation interest with Ohio land use. a Bombus fervidus, b B. perplexus, c B. vagans, $\mathbf{d}$ B. auricomus/pensylvanicus. Land use is shown for the state of Ohio (red-developed areas, orange — crop, yellow-herbaceous, green-forest, gray-other; see Methods text for further details on land cover classification). Blue circles represent field survey sites where a species was found, and are sized according to its proportional abundance in field surveys. Gray circles denote sites where a species was not present. The three dominant species that were present at almost all sites are not included here, but see Electronic Supplementary Material (Fig. S1)

not predicted by the amount of forest in the landscape. Occurrence of only one species was significantly predicted by habitat type (planted roadside for $B$. auricomus). The three most common species, Bombus impatiens, B. griseocollis, and B. bimaculatus, were widely distributed and did not show strong geographic patterns in occurrence (see Electronic Supplementary Material Fig. S1 for distribution maps).

\section{Discussion}

We found substantial variation in distribution and abundance of 10 species of bumble bee across the state of Ohio. This survey of over 23,000 bees at $>200$ sites is among the largest state or regional surveys yet reported, and provides a detailed and informative view of Bombus diversity and abundance overall, and at the species level. Abundance of bumble bees responded most strongly with habitat type, though landscape and geographic factors also explained some of the variance. However, these responses varied among species, suggesting ways of tailoring conservation efforts to target taxa of interest. Abundance and diversity were higher overall in planted habitats, including urban and roadside areas, than 
in unplanted habitats. These findings suggest that management efforts to provide forage for bumble bees are both successful and important. However, our results also confirm that some species of bumble bees respond to latitude and the broader landscape setting, especially the amount of forest within $2 \mathrm{~km}$. We know that forest is an important nesting habitat for many of the Midwestern bumble bee species (Lanterman et al. 2019), therefore inclusion of forested habitat in conservation plans is needed to promote nesting of these species and more diverse bumble bee communities in general. Careful siting of flower restorations to provide access to suitable nesting habitat may magnify the value of conservation efforts.

Bumble bee abundance varied strongly among habitat types. However, those effects often depended on other variables, such as latitude and landscape-level forest cover. This makes sense for bumble bees because they have a long colony cycle and foraging ranges that are large enough to exceed habitat boundaries (Osborne et al. 1999; Woodgate et al. 2016). Colony success likely depends on access to multiple habitats at different times over the growing season. The positive relationship between total bumble bee abundance and cover of developed land in our study, as well as the high abundance of bumble bees in urban patches, concurs with others' findings that at least some species thrive in humandominated ecosystems (McFrederick and LeBuhn 2006; Ahrné et al. 2009; Reeher et al. 2020). Management of urban plantings for aesthetically pleasing blooms may result in more diverse, consistent, and concentrated flower resources that promote colony success compared to agricultural and natural non-urban landscapes (Goulson et al. 2002; Samuelson et al. 2018).

Planted habitats had higher abundance and diversity of Bombus, suggesting that management efforts to promote pollinators are having positive effects. Restored meadows hosted abundant and diverse bumble bee communities commensurate with their profusion of attractive, rewarding wildflowers. Although usually smaller in size, urban patches of wildflowers had similar numbers of bumble bees as restored meadows. Planted hayfields, which were typically monocultures of red clover (Trifolium pratense) or alfalfa (Medicago sativa), yielded more than twice as many bumble bees as the average survey of unplanted natural early-successional fields or shrubby old fields. Planted hayfields, and to a lesser extent some roadsides, may have supported higher abundance because they exhibited sustained blooms of weedy flowers that are known bumble bee food plants (especially plants in the family Fabaceae, like Trifolium spp., Melilotus spp., Vicia spp., and Lathyrus spp.). Changes in management and decreasing abundance of hayfields in other areas of the northern USA have been associated with declines in occurrence and range of B. pensylvanicus, as well as B. fervidus (Richardson et al. 2019; Wood et al 2019). Likewise, flower restorations near agricultural areas that complement them in bloom times promoted bumble bee abundance, diversity, and colony success (Carvell et al. 2007, 2011; Williams et al. 2015; Wood et al. 2015).

Sites that are dominated by weedy herbaceous vegetation and are mowed one to several times per season, such as hayfields and roadsides, provide repeated pulses of high-density forage (Carvell et al. 2006). However, the high level of disturbance may also destroy sheltered nest sites and overwintering locations and thereby reduce their capacity to support nests of most species. Therefore, although we found that they attract large numbers of foragers of many species, these habitats may be unsuitable for supporting long-term population growth unless the surrounding landscape offers nesting and overwintering opportunities. Indeed, we found that the raw diversity of bumble bees along unplanted and planted roadsides increased with increased forest cover in the surrounding landscape (Electronic Supplementary Materials, Table S3). Forest positively affected species that nest in or near forest in our study, but not a species of conservation interest that nests in open grasslands, 
B. pensylvanicus (Fig. 4). Promoting populations of grassland-nesting species may require appropriate timing of mowing, in addition to protection or provisioning of nesting resources. The question of whether habitats with abundant foragers but few nesting opportunities are ecological sinks is beyond the scope of this study, but deserves research focus.

Bumble bee abundance in our surveys, but not diversity, increased over the season, most likely reflecting growth in colony size. The addition of later emerging species, such as $B$. griseocollis, B fervidus, B. pensylvanicus and B. auricomus (Colla and Dumesh 2010) also contributed to the increase in abundance and especially to the diversity of bumble bee communities through June. In August several species appeared to have completed their colony cycle, so species diversity declined. This resulted in communities dominated by $B$. impatiens, which is currently known to continue its colony cycle into the fall (Colla and Dumesh 2010). In the past, the reduction in species richness may not have been as noticeable, since $B$. affinis (now apparently absent from the state) and other declining species (e.g., B. vagans and B. fervidus) were once abundant late into the fall (Macior 1969; Colla and Dumesh 2010). When monitoring for the presence of rare species, surveying the tail ends of the season in spring and fall remains essential. However, our late-season surveys did not offer useful insights into the habitat and geographic patterns of all species. By recognizing seasonal changes and limiting analyses to the times of peak diversity when most species were well-represented we were better able to evaluate the overall responses of bumble bee communities to the environment.

\section{Species specific patterns}

The predominance of Bombus impatiens was consistent across all habitats and increased over the season. Other studies of bumble bee communities in eastern North America have found similar dominance of $B$. impatiens and suggest that this species is increasing in relative abundance compared to other species (Colla and Packer 2008; Cameron et al. 2011; Jacobson et al. 2018; Richardson et al. 2019). No clear explanation for the success of $B$. impatiens has surfaced, though our results suggest that its highly general habitat use and long season of activity help it maintain large populations in many landscape contexts. In turn, large populations likely buffer this species from loss of genetic diversity and demographic stochasticity that can lead to population decline (Herrmann et al. 2007; Dreier et al. 2014). High diversity in worker size within $B$. impatiens nests may also allow colonies to respond more efficiently than some other species to environmental changes (Austin and Dunlap 2019), like fluctuations in food availability. Bombus griseocollis and B. bimaculatus were also consistently present and abundant across our surveys. All three of these potential competitors were abundant in the same habitats, raising the question of what subtle differences in their biology allow them to coexist. Our findings demonstrate that these three common Bombus species respond differently to habitat management and landscape. Bombus impatiens showed fewer distinct responses than the other two species (Fig. 2), seeming to flourish in almost all habitats. In contrast, Bombus griseocollis responded positively to forested landscapes in planted meadow or shrubby habitats, and showed GDDspecific increases in planted meadow habitats (perhaps where its favored milkweed food plants (Villalona et al. 2020) were abundant). Bombus bimaculatus responded differently, with an increase at high latitudes, varied responses to GDD-habitat combinations, and an earlier peak in abundance. Although there are certainly broad similarities in these three dominant species, recognizing their differences will be necessary for effective conservation of bumble bee communities. When generalizing about the response of a taxonomic group 
to habitat quality, teasing apart species-specific effects helps to avoid attributing to all species patterns that are driven primarily by the dominant species. Analysis of species-specific foraging preferences may reveal further differences in their niches.

Several species of bumble bee that were found frequently in our survey of Ohio are thought to be declining or rare in other areas. Two of these, B. vagans and B. fervidus were each found in $>37 \%$ of our surveys (for reports of decline elsewhere see Grixti et al. 2009; Williams et al. 2009; Colla and Packer 2008; Colla et al. 2012; Bartomeus et al. 2013; Bushmann and Drummond 2015; Jacobson et al. 2018). On the other hand, our results agree with those of others that $B$. perplexus is relatively uncommon (Colla and Packer 2008; Williams et al. 2009), found in only $21 \%$ of surveys. Due to the lack of rigorous historical datasets on bee abundance and diversity in Ohio, we were not able to investigate temporal trends in abundance as has been done in other recent literature (Colla and Packer 2008; Grixti et al. 2009; Cameron et al. 2011; Colla et al. 2012; Jacobson et al. 2018; Richardson et al. 2019; Wood et al. 2019). Though the stability of various species' populations is outside of the scope of this paper our results provide species-specific abundance and distribution data that could be useful for future population stability analyses. In places that lack historical data for comparison, such as Ohio, what we can do is focus on how current bee distributions reflect current environments and use these data to inform conservation strategies.

Although our survey was extensive, we did not have enough observations of the rarer species to evaluate confidently possible influences on their abundance. This result is sobering considering the scope of our study; we had $>450 \mathrm{~h}$ of observation over two years, which provided $>23,000$ bumble bee sightings, a level of sampling that is expensive and uncommon. It is not clear whether rarity of these species is consistent with historical patterns, reflects recent declines in their abundance, or is especially apparent because of increased abundances of the three most common species. Nonetheless, we were able to detect marked patterns regarding occurrence (presence/absence) and biogeography of the rarer bumble bees. Bombus perplexus, which favored forested landscapes and the northern part of the state, was associated with urban wildflower plantings. Bombus vagans and $B$. fervidus were also more common in forested landscapes and at northern latitudes, but not associated with urban patches. A species of conservation concern, B. pensylvanicus (MacPhail et al. 2020; Richardson et al. 2019), that is affiliated with grasslands in our and other studies (Colla and Dumesh 2010; Williams et al. 2014), was more frequently found in the southern part of the state. Therefore, conserving or enhancing grassland habitat with flowering forbs may be enough in the southern part of the state to support diversity, but in the north habitat improvements near forests may be particularly effective.

One of the motivations for this survey was a desire to document the current distribution and abundance of rare species, especially Bombus affinis and B. terricola. The former species was once common in Ohio and was recently listed as federally endangered in the USA, as a result of precipitous declines after about the year 1999 (Colla and Packer 2008; Grixti et al. 2009; Williams et al. 2009; Cameron et al. 2011; Colla et al. 2012; Jacobson et al. 2018). Our results do not provide evidence that either of these species is now surviving in Ohio. However, B. affinis has been observed in low abundance in the past several years in the nearby states of Iowa, Illinois, Minnesota, and Wisconsin and in isolated mountain meadows in Virginia and West Virginia (S. Droege, personal communication; P. Reeher, personal observations in Virginia). Therefore, further monitoring may yet reveal its continued presence or recolonization in Ohio. 


\section{Conclusions}

Intensive sampling generates detailed datasets that can be used to improve monitoring and habitat enhancements. In Ohio, the three most common species are nearly ubiquitous, while distributions of three less common species vary with latitude and forest cover. More observations of the rarer species are needed to understand how environmental factors influence their abundances here and across the region. Our finding that some species reach their highest abundance in non-roadside habitats cautions that monitoring focused entirely along roadsides could underestimate the abundance and distribution of some species of interest. Our results provide a strong starting point for future bumble bee monitoring and for conservation intervention that targets less common species. While many surveys are or will be funded and motivated by state-level conservation needs, important patterns in bumble bee diversity and abundance need to also be considered at a broader geographic scale. There is a strong need for collaboration among those conducting state-wide surveys to synthesize regional and national data sets to address broad scale questions.

Supplementary Information The online version of this article (https://doi.org/10.1007/s10531-021-02121 -x) contains supplementary material, which is available to authorized users.

Acknowledgements This study was funded by the Ohio Department of Transportation (ODOT) grant number 30571. We thank Matt Perlik, Adrienne Earley, Megan Michael, and Phoenix Golnick Neal at ODOT for initiating the project and providing guidance throughout. We appreciate the cooperation of Ohio State Parks and Nature Preserves, Cuyahoga Valley National Park, Wayne National Forest, many county and municipal parks districts, and many private landowners who provided access to study sites. We are grateful to the following student workers who assisted with field work: Audrey Bezilla, Sam Blechman, Jules Christensen, Kevin Conroy, Christa Curtiss, Elizabeth DiCesare, John Ertle, Derek Foster, Amber Fredenburg, Samantha Hodgson, Marko Jesenko, Kelly Peterson, and Brad Small. We also thank Denise Ellsworth of Ohio State University Extension for help in publicizing the project and recruiting private land owners to participate. John Ballas provided comments on earlier drafts of this manuscript.

Author contributions The Ohio Department of Transportation initiated this research. KG, RJM, JN, PR, AL, and MV designed the study. All authors collected the data. JN, RJM, and KG analyzed the data, and wrote the first draft of the manuscript. All authors helped revise the manuscript and approved the final draft.

Funding This study was funded by the Ohio Department of Transportation.

Data availability Our dataset from this study is publicly available on the online scientific data repository Open Science Framework at https://osf.io/ygd9m/.

\section{Compliance with ethical standards}

Conflict of interest The authors have no conflicts of interest.

Ethical approval This manuscript is the authors' own original research and has not been submitted or published elsewhere simultaneously.

Informed consent All authors consent to the submission of this manuscript to the $\mathrm{J}$ Insect Conserv. All authors consent to the publication of this manuscript if accepted in Biodiversity and Conservation.

Open Access This article is licensed under a Creative Commons Attribution 4.0 International License, which permits use, sharing, adaptation, distribution and reproduction in any medium or format, as long as you give appropriate credit to the original author(s) and the source, provide a link to the Creative Commons licence, and indicate if changes were made. The images or other third party material in this article are included in the article's Creative Commons licence, unless indicated otherwise in a credit line to the material. If material is not included in the article's Creative Commons licence and your intended use is not 
permitted by statutory regulation or exceeds the permitted use, you will need to obtain permission directly from the copyright holder. To view a copy of this licence, visit http://creativecommons.org/licenses/by/4.0/.

\section{References}

Ahrné K, Bengtsson J, Elmqvist T (2009) Bumble bees (Bombus spp.) along a gradient of increasing urbanization. PLoS ONE 4(5):e5574. https://doi.org/10.1371/journal.pone.0005574

Austin MW, Dunlap AS (2019) Intraspecific variation in worker body size makes North American bumble bees (Bombus spp.) less susceptible to decline. Am Nat 194(3):381-394

Bartomeus I, Ascher JS, Gibbs J, Danforth BN, Wagner DL, Hedtke SM, Winfree R (2013) Historical changes in northeastern US bee pollinators related to shared ecological traits. PNAS 110(12):4656-4660

Bushmann SL, Drummond FA (2015) Abundance and diversity of wild bees (Hymenoptera: Apoidea) found in lowbush blueberry growing regions of Downeast Maine. Environ Entomol 44(4):975-989

Cameron SA, Sadd BM (2020) Global trends in bumble bee health. Annu Rev Entomol 65:209-232

Cameron SA, Lozier JD, Strange JP, Koch JB, Cordes N, Solter LF, Griswold TL (2011) Patterns of widespread decline in North American bumble bees. PNAS 108(2):662-667

Cameron SA, Lim HC, Lozier JD, Duennes MA, Thorp R (2016) Test of the invasive pathogen hypothesis of bumble bee decline in North America. Proceedings of the National Academy of Sciences 113 (16):4386-4391

Cariveau DP, Winfree R (2015) Causes of variation in wild bee responses to anthropogenic drivers. Curr Opin Insect Sci 10:104-109

Carvell C, Roy DB, Smart SM, Pywell RF, Preston CD, Goulson D (2006) Declines in forage availability for bumblebees at a national scale. Biol Conserv 132:481-489

Carvell C, Meek WR, Pywell RF, Goulson D, Nowakowski M (2007) Comparing the efficacy of agri-environment schemes to enhance bumble bee abundance and diversity on arable field margins. J Appl Ecol 44:29-40

Carvell C, Osborne JL, Bourke AFG, Freeman SN, Pywell RF, Heard MS (2011) Bumble bee species' responses to a targeted conservation measure depend on landscape context and habitat quality. Ecol Appl 21(5):1760-1771

Christopher TR (2016) Status for Rusty Patched Bumble Bee, Federal Register 82(7):3186-3208, Fish and Wildlife Service, Endangered and Threatened Wildlife and Plants; Endangered Species, Department of the interior 50 CFR Part 17, [Docket No. FWS-R3-ES-2015-0112; 4500030113] RIN 1018-BB66

Colla SR, Dumesh S (2010) The bumble bees of Southern Ontario: notes on natural history and distribution. J Entomol Soc Ont 141:39-68

Colla SR, Packer L (2008) Evidence for decline in eastern North American bumblebees (Hymenoptera: Apidae), with special focus on Bombus affinis Cresson. Biodivers Conserv 17:1379-1391

Colla SR, Richardson L, Williams PH (2011) Bumble bees of the eastern United States. US Department of Agriculture Pollinator Partnership

Colla SR, Gadallah F, Richardson L, Wagner D, Gall L (2012) Assessing declines of North American bumble bees (Bombus spp.) using museum specimens. Biodivers Conserv 21:3585-3595

Dohzono I, Suzuki K (2010) Morphological and genetic differentiation in Isodon umbrosus by altitudinal variation in bumblebee pollinator assemblages. Plant Spec Biol 25:20-29

Dramstad WE (1996) Do bumblebees (Hymenoptera: Apidae) really forage close to their nests? J Insect Behav 9:163-182

Dreier S, Redhead JW, Warren IA, Bourke AFG, Heard MS, Jordan WC, Sumner S, Wang J, Carvell C (2014) Fine-scale spatial genetic structure of common and declining bumble bees across an agricultural landscape. Mol Ecol 23:3384-3395

ESRI (2016) ArcGIS Desktop: Release 10.3.0.4322 Environmental Systems Research Institute, Redlands, California

Goulson D (2010) Bumblebees: behaviour, ecology, and conservation. Oxford University Press, Oxford

Goulson D, Hughes WHO, Derwent LC, Stout JC (2002) Colony growth of the bumblebee, Bombus terrestris, in improved and conventional agricultural and suburban habitats. Oecologia 130:267-273

Goulson D, Lye GC, Darvill B (2008) Decline and conservation of bumble bees. Annu Rev Entomol 53:191-208 
Goulson D, Nicholls E, Botías C, Rotheray EL (2015) Bee declines driven by combined stress from parasites, pesticides, and lack of flowers. Science 347(6229):e1255957. https://doi.org/10.1126/scien ce. 1255957

Grixti JC, Wong LT, Cameron SA, Favret C (2009) Decline of bumble bees (Bombus) in the North American Midwest. Biol Conserv 142:75-84

Hatfield, R, Jepsen S, Thorp R, Richardson L, Colla S, Foltz Jordan S, Evans E (2015) Bombus affinis. The IUCN Red List of Threatened Species 2015: e.T44937399A46440196. https://doi.org/10.2305/IUCN. UK.2015-2.RLTS.T44937399A46440196.en

Heard MS, Carvell C, Carreck NL, Rothery P, Osborne JL, Bourke AFG (2007) Landscape context not patch size determines bumble-bee density on flower mixtures sown for agri-environment schemes. Biol Lett 3:638-641

Heinrich B (1976) The foraging specializations of individual bumblebees. Ecol Monogr 46:105-128

Herrmann F, Westphal C, Moritz RFA, Steffan-Dewenter I (2007) Genetic diversity and mass resources promote colony size and forager densities of a social bee (Bombus pascuourum) in agricultural landscapes. Mol Ecol 16:1167-1178

Hines HM (2008) Historical biogeography, divergence times, and diversification patterns of bumble bees (Hymenoptera: Apidae: Bombus). Syst Biol 57:58-75

Hines HM, Hendrix SD (2005) Bumble bee (Hymenoptera: Apidae) diversity and abundance in tallgrass prairie patches: effects of local and landscape floral resources. Environ Entomol 34(6):1477-1484

Hobbs GA (1965) Ecology of species of Bombus Latr. (Hymenoptera: Apidae) in Southern Alberta. II. Subgenus Bombias Robt. Can Entomol 97:120-128

Homer CG, Dewitz JA, Yang L, Jin S, Danielson P, Xian G, Coulston J, Herold ND, Wickham JD, Megown K (2015) Completion of the 2011 National Land Cover Database for the conterminous United StatesRepresenting a decade of land cover change information. Photogramm Eng Rem S 81:345-354

Jacobson MM, Tucker EM, Mathiasson ME, Rehan SM (2018) Decline of bumble bees in northeastern North America, with special focus on Bombus terricola. Biol Conserv 217:437-445

JMP®, version 14 (2018) SAS Institute Inc., Cary, NC, 1989-2019

Kerr JT, Pindar A, Galpern P, Packer L, Potts SG, Roberts SM, Rasmont P, Schweiger O, Colla SR, Richardson LL, Wagner D, Gall LF, Sikes DS, Pantoja A (2015) Climate change impacts on bumble bees converge across continents. Science 349(6244):177-180

Kremen C, Williams NM, Aizen MA, Gemmill-Herren B, LeBuhn G, Minckley R, Packer L, Potts SG, Roulston T, Steffan-Dewenter I, Vázquez D, Winfree R, Adams L, Crone EE, Greenleaf SS, Keitt TH, Klein A, Regetz J, Ricketts TH (2007) Pollination and other ecosystem services produced by mobile organisms: a conceptual framework for the effects of land-use change. Ecol Lett 10:299-314

Lanterman J, Reeher P, Mitchell RJ, Goodell K (2019) Habitat preference and phenology of nest seeking and foraging spring bumble bee queens in Northeastern North America (Hymenoptera: Apidae: Bombus). Am Midl Nat 182:131-159

Lenth RV (2016) Least-Squares Means: The R Package lsmeans. J Stat Softw 69(1):1-33

Liczner AR, Colla SR (2020) One-size does not fit all: at-risk bumble bee habitat management requires species-specific local and landscape considerations. Insect Conserv Divers. https://doi.org/10.1111/ icad.12419

Losey JE, Vaughan M (2006) The economic value of ecological services provided by insects. Bioscience 56(4):311-323

Macior LW (1969) Pollination adaptation in Pedicularis lanceolata. Am J Bot 56(8):853-859

MacPhail VJ, Gibson SD, Colla SR (2020) Community science participants gain environmental awareness and contribute high quality data but improvements are needed: Insights from Bumble Bee Watch. PeerJ 8:e9141

McCune B, Grace JB, Urban DL (2002) Analysis of ecological communities. MjM Software Design, Gleneden Beach

McFrederick QS, LeBuhn G (2006) Are urban parks refuges for bumble bees Bombus spp. (Hymenoptera: Apidae)? Biol Conserv 129:372-382

McGrady CM, Troyer R, Fleischer SJ (2020) Wild bee visitation rates exceed pollination thresholds in commercial Cucurbita agroecosystems. J Econ Entomol 113(2):562-574

Newcomb L (1989) Newcomb's wildflower guide. Little, Brown and Company, Boston

ODNR Division of Wildlife (2020) Wildlife districts. https://wildlife.ohiodnr.gov/portals/wildlife/pdfs/publi cations/information/pub318.pdf. Accessed 1 May 2020

Oksanen J, Blanchet FG, Friendly M, Kindt R, Legendre P, McGlinn D, Minchin PR, O'Hara RB, Simpson GL, Solymos P, Stevens MHH, Szoecs E, Wagner H (2016) Vegan: Community ecology package. R package version 2.4-1. https://CRAN.R-project.org/package=vegan. Accessed 1 Jan 2017 
Osborne JL, Clark SJ, Morris RJ, Williams IH, Riley JR, Smith AD, Reynolds DR, Edwards AS (1999) A landscape-scale study of bumble bee foraging range and constancy, using harmonic radar. J Appl Ecol 36:519-533

Park MG, Raguso RA, Losey JE, Danforth BN (2016) Per-visit pollinator performance and regional importance of wild Bombus and Andrena (Melandrena) compared to the managed honey bee in New York apple orchards. Apidologie 47:145-160

Preston FW (1948) The commonness, and rarity, of species. Ecology 29:254-283

R Development Core Team (2019) R: A language and environment for statistical computing. R Foundation for Statistical Computing, Vienna, Austria. v3.5.3. https://www.r-project.org. Accessed 1 Mar 2019

Reeher P, Lanterman Novotny J, Mitchell RJ (2020) Urban bumble bees are unaffected by the proportion of intensely developed land within urban environments of the industrial Midwestern USA. Urban Ecosyst. https://doi.org/10.1007/s11252-020-00965-9

Richardson JE (2011) Eta squared and partial eta squared as measures of effect size in educational research. Educ Res Rev 6(2):135-147

Richardson LL, McFarland KP, Zahendra S, Hardy S (2019) Bumble bee (Bombus) distribution and diversity in Vermont, USA: a century of change. J Insect Conserv 23(1):45-62

Roberts DW (2016) Labdsv: ordination and multivariate analysis for ecology. R package version 1.8-0. https ://CRAN.R-project.org/package=labdsv. Accessed 1 Mar 2019

Ropars L, Affre L, Schurr L, Flacher F, Genoud D, Mutillod C, Geslin B (2020) Land cover composition, local plant community composition and honeybee colony density affect wild bee species assemblages in a Mediterranean biodiversity hot-spot. Acta Oecol 104:103546. https://doi.org/10.1016/j.actao .2020.103546

Roulston TH, Goodell K (2011) The role of resources and risks in regulating wild bee populations. Annu Rev Entomol 56:293-312

Russell AL, Buchmann S, Papaj DR (2017) How a generalist bee achieves high efficiency of pollen collection on diverse floral resources. Behav Ecol 28(4):991-1003

Samuelson AE, Gill RJ, Brown MJF, Leadbeater E (2018) Lower bumblebee colony reproductive success in agricultural compared to urban environments. Proc R Soc B 285:20180807

Saville NM (1993) Bumblebee ecology in woodlands and arable farmland. PhD Dissertation, University of Cambridge

Schochet AB, Hung K-LJ, Holway DA (2016) Bumble bee species exhibit divergent responses to urbanization in a Southern California landscape. Ecol Entomol 41:685-692

United States Department of Agriculture, National Agricultural Statistics Service (2019) CropScape: cropland data layer. https://nassgeodata.gmu.edu/CropScape/. Accessed 1 Mar 2019

United States Department of Agriculture, National Agricultural Statistics Service (2019) State agricultural review: Ohio. https://www.nass.usda.gov/Quick_Stats/Ag_Overview/stateOverview.php?state=OHIO. Accessed 29 Jun 2020

United States Fish and Wildlife Service (2017) Survey protocols for the Rusty Patched Bumble Bee (Bombus affinis). Version 1.1

Villalona E, Ezray BD, Laveaga E, Agrawal AA, Ali JG, Hines HM (2020) The role of toxic nectar secondary compounds in driving differential bumble bee preferences for milkweed flowers. Oecologia 193:619-630

Walther-Hellwig K, Frankl R (2000) Foraging distances of Bombus muscorum, Bombus lapidarius, and Bombus terrestris (Hymenoptera, Apidae). J Insect Behav 13:239-246

Walther-Hellwig K, Frankl R (2000) Foraging habitats and foraging distances of bumblebees, Bombus spp. (Hym., Apidae) in an agricultural landscape. J Appl Entomol 124:299-306

Ward K, Cariveau D, May E, Roswell M, Vaughan M, Williams N, Winfree R, Isaacs R, Gill K (2014) Streamlined bee monitoring protocol for assessing pollinator habitat. The Xerces Society for Invertebrate Conservation, Portland

Williams PH, Osborne JL (2009) Bumblebee vulnerability and conservation world-wide. Apidologie 40(3):367-387

Williams P, Colla S, Xie Z (2009) Bumblebee vulnerability: common correlates of winners and losers across three continents. Conserv Biol 23(4):931-940

Williams PH, Thorp RW, Richardson LL, Colla SR (2014) Bumble bees of North America: an identification guide (Princeton Field Guides). Princeton University Press, Oxsfordshire

Williams NM, Ward KL, Pope N, Isaacs R, Wilson J, May EA, Ellis J, Daniels J, Pence A, Ullmann K, Peters J (2015) Native wildflower plantings support wild bee abundance and diversity in agricultural landscapes across the United States. Ecol Appl 25:2119-2131

Woodgate JL, Makinson JC, Lim KS, Reynolds AM, Chittka L (2016) Life-long radar tracking of bumblebees. PLoS ONE 11(8):e0160333. https://doi.org/10.1371/journal.pone.0160333 
Wood TJ, Holland JM, Hughes WOH, Goulson D (2015) Targeted agri-environment schemes significantly improve the population size of common farmland bumblebee species. Mol Ecol 24:1668-1680

Wood TJ, Gibbs J, Graham KK, Isaacs R (2019) Narrow pollen diets are associated with declining Midwestern bumble bee species. Ecology 100(6):e02697. https://doi.org/10.1002/ecy.2697

Publisher's Note Springer Nature remains neutral with regard to jurisdictional claims in published maps and institutional affiliations.

\section{Authors and Affiliations}

\section{Jessie Lanterman Novotny ${ }^{1,3}$ (D) $\cdot$ Paige Reeher ${ }^{2,4}$ (D) $\cdot$ Megan Varvaro ${ }^{1}$ (D)

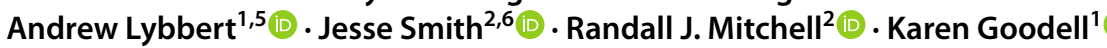

1 The Ohio State University (Evolution, Ecology, \& Organismal Biology), Columbus, OH, USA

2 The University of Akron (Biology), Akron, OH, USA

3 Hiram College (Biology), Hiram, OH, USA

4 Environmental Solutions \& Innovations, Inc., Ravenna, OH, USA

5 Methodist University (Biology), Fayetteville, NC, USA

6 Illinois State University (Behavior, Ecology, Evolution, and Systematics), Normal, IL, USA 